\title{
High-resolution optical coherence tomography imaging of the living kidney
}

\author{
Peter M Andrews ${ }^{1}$, Yu Chen ${ }^{2}$, Maristela L Onozato' ${ }^{1}$, Shu-Wei Huang ${ }^{2}$, Desmond C Adler ${ }^{2}$, Robert A Huber ${ }^{2,3}$, \\ James Jiang ${ }^{4}$, Scott E Barry ${ }^{4}$, Alex E Cable ${ }^{4}$ and James G Fujimoto ${ }^{2}$
}

Optical coherence tomography (OCT) is a rapidly emerging imaging modality that can provide non-invasive, crosssectional, high-resolution images of tissue morphology in situ and in real-time. In the present series of studies, we used a high-speed OCT imaging system equipped with a frequency-swept laser light source (1.3 $\mu \mathrm{m}$ wavelength) to study living kidneys in situ. Adult, male Munich-Wistar rats were anesthetized, a laparotomy was performed and the living kidneys were exposed for in situ observation. We observed the kidneys prior to, during and following exposure to renal ischemia induced by clamping the renal artery. The effects of intravenous mannitol infusion $(1.0 \mathrm{ml}$ of $25 \%)$ prior to and during renal ischemia were also studied. Finally, living kidneys were flushed with a renal preservation solution, excised and observed while being stored at $0-4^{\circ} \mathrm{C}$. Three-dimensional OCT data sets enabled visualization of the morphology of the uriniferous tubules and the renal corpuscles. When renal ischemia was induced, OCT revealed dramatic shrinkage of tubular lumens due to swelling of the lining epithelium. Three-dimensional visualization and volumetric rendering software provided an accurate evaluation of volumetric changes in tubular lumens in response to renal ischemia. Observations of kidneys flushed with a renal preservation solution and stored at $0-4^{\circ} \mathrm{C}$ also revealed progressive and significant loss of tubular integrity over time. Intravenous infusion of mannitol solution resulted in thinning of the tubular walls and an increase in the tubular lumen diameters. Mannitol infusion also prevented the cell swelling that otherwise resulted in shrinkage of proximal tubule lumens during ischemia. We conclude that OCT represents an exciting new approach to visualize, in real-time, pathological changes in the living kidney in a non-invasive fashion. Possible clinical applications are discussed.

Laboratory Investigation (2008) 88, 441-449; doi:10.1038/labinvest.2008.4; published online 11 February 2008

KEYWORDS: ischemia; kidney; optical coherence tomography (OCT); renal pathology; three-dimensional imaging; renal transplantation

Optical coherence tomography (OCT) is a non-invasive, high-resolution, cross-sectional and three-dimensional (3D) imaging modality that measures the echo delay of light to generate images. ${ }^{1}$ OCT provides dramatic improvements in resolution compared with ultrasound ${ }^{2}$ and can be performed using small diameter, catheter-like probes. ${ }^{3,4}$ Although the light scattering properties of biological tissue typically limits penetration to less than $2 \mathrm{~mm}$, this imaging depth has proven sufficient to provide valuable information about tissue pathology in a number of biomedical fields including ophthalmology, ${ }^{5-7}$ cardiology ${ }^{8,9}$ and gastroenterology. ${ }^{10-13}$

In a recent series of studies, we described the ability of OCT to image the internal microstructure of rat kidneys that had been preserved by vascular perfusion techniques. ${ }^{14}$ Our studies revealed that OCT accurately images the uriniferous tubules and renal corpuscles and provides novel 3D views previously seen only by scanning electron microscopy. ${ }^{15}$ Furthermore, OCT imaging of preserved samples that had been subjected to an ischemic or nephrotoxic insult revealed characteristic histopathological alterations, including changes in tubular dimensions and the presence of cytoplasmic debris within the tubule lumens. ${ }^{14}$

Although the foregoing study demonstrated the ability of OCT to image kidney pathology in preserved samples, if OCT is to be used as a non-invasive procedure for studying kidney pathology in vivo, its applicability to imaging the

\footnotetext{
${ }^{1}$ Department of Biochemistry, Molecular and Cellular Biology, Georgetown University Medical Center, Washington, DC, USA; ${ }^{2}$ Department of Electrical Engineering and Computer Science and Research Laboratory of Electronics, Massachusetts Institute of Technology, Cambridge, MA, USA; ${ }^{3}$ Lehrstuhl für BioMolekulare Optik, Fakultät für Physik, Ludwig-Maximilians-Universität München, München, Germany and ${ }^{4}$ Thorlabs Inc., Newton, NJ, USA

Correspondence: Professor PM Andrews, PhD, Department of Biochemistry, Molecular and Cellular Biology, Georgetown University Medical Center, 3900 Reservoir Road, NW, Washington, DC 20007, USA. E-mail: andrewsp@georgetown.edu

Received 07 August 2007; revised 26 November 2007; accepted 02 December 2007
} 
living kidney must be evaluated. In the present study, we therefore investigated the ability of OCT to image living kidneys prior to, during and following an ischemic insult. We also recorded the changes in renal tubular dimensions induced by the infusion of mannitol and observed the effects of mannitol in preserving proximal tubule integrity during ischemia. ${ }^{16}$ Finally, we observed kidneys that had been flushed with a renal preservation solution, excised and preserved at $0-4^{\circ} \mathrm{C}$. The rat kidney model was chosen because of the wealth of pathological data previously published using this model.

Three-dimensional OCT (3D-OCT) data sets enabled the generation of en face images as well as 3D renderings of the superficial uriniferous tubules and glomeruli. Image analysis provided accurate quantitative information regarding changes in the uriniferous tubules in response to an ischemic insult. Since such changes can be used to predict posttransplant renal function, ${ }^{17}$ our observations suggest a possible application of OCT in evaluating the status of kidneys prior to their transplantation.

\section{MATERIALS AND METHODS}

\section{Optical Coherence Tomography Imaging}

A high-speed OCT system using swept source/Fourier domain detection ${ }^{18-20}$ that enables 3D OCT imaging in vivo was used in this study. Figure 1 is the schematic representation of the swept source OCT imaging system. The light source was a Fourier-domain mode-locked (FDML) frequency swept laser light source generating a $90 \mathrm{~nm}$ full width at half maximum (FWHM) sweep bandwidth at approximately $1290 \mathrm{~nm}$, yielding an $8 \mu \mathrm{m}$ axial image resolution in tissue. ${ }^{21}$ The laser operated at a sweep repetition rate of $42 \mathrm{kHz}$ with an average output power of $12 \mathrm{~mW}$. The imaging was performed using an OCT microscope and imaging engine, modified from a commercially available OCT system (Thorlabs Inc., NJ, USA).

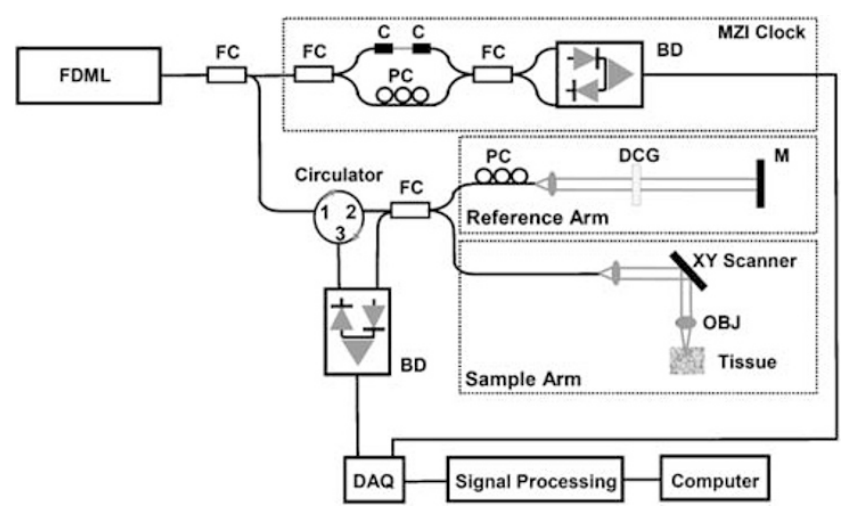

Figure 1 Schematic representation of the swept-source OCT setup. FDML: Fourier-domain mode-locking laser; FC: fiber coupler; PC: polarization controller; C: collimator; MZI: Mach-Zehnder interferometer; M: mirror; BD: balanced detector; DAQ: data acquisition board; DCG: dispersion compensating glasses; OBJ: objective.
Three percent of the laser output power is coupled to a Mach-Zehnder interferometer (MZI) that is used to generate a clock signal for recalibration of the OCT signal on a uniformly-spaced optical frequency grid. ${ }^{20,22}$ Axial scan information is obtained by Fourier transforming the recalibrated OCT signal. ${ }^{20}$ The other $97 \%$ of the laser power is divided equally and delivered to the sample and reference arms of a Michelson interferometer. Imaging of the tissue samples is performed using a pair of mirrors mounted to XY scanning galvanometers (Cambridge Technology, MA, USA) and a microscope objective. A polarization controller and a spatial aperture are used to set the reference arm power. The system sensitivity is $93 \mathrm{~dB}$ with $6 \mathrm{~mW}$ of average power incident on the sample. Dispersion compensating glasses (SFL6) are inserted in the reference arm to compensate for the collimating and focusing optics in the sample arm, which is necessary to obtain an optimal imaging resolution. The resolution for the imaging system is measured to be $8 \mu \mathrm{m}$ (in tissue) in the axial $(Z)$ direction and $5 \mu \mathrm{m}$ in the transverse (XY) directions. Individual cross-sectional OCT images (XZ) consisting of 512 axial scans are generated at a rate of 50 frames per second over ranges of $0.75 \mathrm{~mm}$ in length (X, 512 transverse pixels) and $2.2 \mathrm{~mm}$ in depth ( $\mathrm{Z}$, axial 512 pixels). Consecutive OCT images at different planes along the Y direction are scanned to generate a $3 \mathrm{D}$ volume. The imaging range in $\mathrm{Y}$ is also $0.75 \mathrm{~mm}$ with $512 \mathrm{XZ}$ frames. Therefore, each $3 \mathrm{D}$ volume contains $512 \times 512 \times 512$ pixels with $\mathrm{XYZ}$ dimensions of $0.75 \times 0.75 \times 2.2 \mathrm{~mm}$. The OCT software acquires a series of cross-section OCT images for each 3D volume in approximately $10 \mathrm{~s}$, and can display both crosssectional (XZ) and en face (XY) images immediately after image acquisition. In addition to direct morphological analysis of tubular and glomerular dimensions (averaging open luminal dimensions in a representative image), the $3 \mathrm{D}-\mathrm{OCT}$ data were imported to a separated advanced $3 \mathrm{D}$ visualization software (Amira, Mercury Computer Systems Inc., Berlin, Germany) to generate 3D volumetric views.

\section{Quantitative Measurements}

Since OCT images are stored in digital format, we can perform automatic and interactive image analysis to quantify anatomical features of interest. This approach is similar to those methods used in conventional microscopy/fluorescence microscopy. In this study, we focused on the following quantitative measurements.

\section{Tubular diameters}

In a representative en face OCT image, there are approximately 20-30 tubular lumens in the field of view. The lumens appear either circular or tubular in shape depending on the relative angle between the kidney tubule and the imaging section plane. The diameter of tubule is estimated by measuring the circle diameter in the case of circular shaped lumen, or the smallest distance perpendicular to the two parallel surfaces of the luminal wall in the case of tubular 
shaped lumen, using the measurement toolbox provided by Amira. This measurement function is similar to those in the other advanced software packages for conventional microscopy/fluorescence microscopy. Since they exhibit local variance in luminal size, we averaged the size of 20 lumens evenly distributed in the field of view.

\section{Interstitial volume/tubular volume}

Interstitial volume changes corresponding to the tubular volume. In OCT images, there is distinct difference in the signal intensity between the tubular lumen (low backscattering) and the interstitial tissues or parenchyma (high backscattering). Therefore, we can segment out the tubular lumen using intensity thresholding applied on individual cross-sectional OCT images. We then use 3D visualization and volumetric rendering software (Amira) to visualize the tubular networks. The total tubule luminal volume is quantified by multiplying the total pixel numbers in the segmented 3D image and the pixel size (which is $750 \times 750 \times 2200 \mu \mathrm{m}^{3} / 512^{3}=9.22 \mu \mathrm{m}^{3}$ pixel).

\section{Statistical analysis}

The difference between two groups of measurements is evaluated by one-way analysis of variance (ANOVA) and the $P$-value is presented.

\section{Animal Model}

Studies were performed using male rats of the MunichWistar strain. This strain of rats is unique in having superficial glomeruli accessible for observation. ${ }^{23}$ The rats were studied when they reached approximately 8 weeks of age, at which time they had a median weight of approximately $250 \mathrm{~g}$. The rats were maintained on a standard Purina Rat Chow diet (Ralston Purina Co., St Louis, MO, USA) and ad lib water intake. All rats had normal kidney function as determined by an analysis of serum creatinine (less than or equal to $0.6 \mathrm{mg} / \mathrm{dl})$. The animals were anesthetized with pentobarbital sodium $(100 \mathrm{mg} / \mathrm{kg}$ body weight, i.p.) and placed on a temperature-regulated table. The animals were turned on their right side and a left subcostal flank incision was made to expose the left kidney. A $10 \mathrm{~cm}$ length of 3-0 silk ligature was looped around the left renal artery at its juncture with the abdominal aorta. Gentle tension on this loop was enough to occlude blood flow to the left kidney. This technique allows for the manipulation of blood flow by applying or releasing tension on the silk loop. The femoral vein was cannulated with polyethylene tubing and attached to a $5.0 \mathrm{ml}$ syringe mounted on a syringe pump (Sage Instruments, Model 341A). Using the foregoing protocol, we evaluated the effects of $20 \mathrm{~min}$ ischemia to the left kidney in two animals and the effects of mannitol infusion prior to ischemia in two animals. For each kidney, 36 3D-OCT image data sets were acquired. Following our observations, the rats were euthanized by intravenous infusion of sufficient pentobarbital sodium to induce cardiac arrest.

\section{Mannitol Experiments}

A single bolus of $1.0 \mathrm{ml}$ containing $25 \%$ of mannitol was slowly infused into the femoral vein over a period of $2 \mathrm{~min}$. The response to mannitol infusion was observed and its effects on subsequent renal ischemia (described above) were observed and recorded in two animals.

\section{Preservation of Kidneys}

Four rat kidneys (from two animals) were preserved using a phosphate buffered sucrose solution and vascular perfusion procedures previously described by us. ${ }^{24,25}$ Briefly, a loose ligature was placed around the abdominal aorta at a point just above the renal arteries, the inferior vena cava was cut and a flushing solution consisting of cooled $\left(0-4^{\circ} \mathrm{C}\right)$ phosphate buffer $\left(4.3 \mathrm{~g} / \mathrm{l} \mathrm{NaH} \mathrm{NO}_{4}\right.$ and $\left.14.8 \mathrm{~g} / \mathrm{N} \mathrm{NaH}_{2} \mathrm{PO}_{4}\right)$ containing $150 \mathrm{mOsm}$ sucrose was perfused retrograde through the aorta at a pressure of $140 \mathrm{mmHg}$. Immediately following flushing with the phosphate buffered sucrose preservation solution $(<1 \mathrm{~min})$, the kidneys were excised, placed in translucent plastic bags containing the flushing solution and maintained at $0-4^{\circ} \mathrm{C}$ in an ice chest.

\section{Note}

All the animal model, surgical fixation and euthanasia procedures had received prior approval by the 'Committee on Animal Care' at the Massachusetts Institute of Technology (MIT), in compliance with the Federal Animal Welfare Act.

\section{RESULTS}

\section{Normal Kidney}

With the anesthetized rat secured to a dissecting table in a supine position, a laparotomy was performed and the left kidney exposed for viewing. The superficial living uriniferous tubules were immediately visible using OCT. Cross-sectional OCT images provided views of four to five layers of the superficial uriniferous tubules (Figure 2). En face OCT images revealed tubular luminal sizes and shapes as well as the thickness of the intervening tubular walls (Figure 3a). Glomeruli are easily distinguished by their larger size $(150 \mu \mathrm{m})$, nearly spherical shape and by being separated from the surrounding parenchyma by the capsular space of Bowman (Figure 3a). Based on their size and location, OCT also revealed what appear to be glomerular arterioles entering and leaving the vascular pole of the renal corpuscle (Figure 3a). We measured the size of the tubular lumens in the representative en face OCT images (approximately 20-30 lumens per image). The average luminal diameters of these tubules was $25.7 \pm 5.1 \mu \mathrm{m}$, which approximates a statistical analysis of rat kidney tubule luminal diameters in vascular perfusion fixed samples. ${ }^{25}$ Figure $3 \mathrm{~b}$ shows a corresponding light microscopic image of a rat kidney. Although there is some shrinkage of the size of the glomeruli and volume of interstitial tissue due to the histological process, OCT correlates well with the light microscopic image. Also, the size of lumen remains almost identical after histology processing 


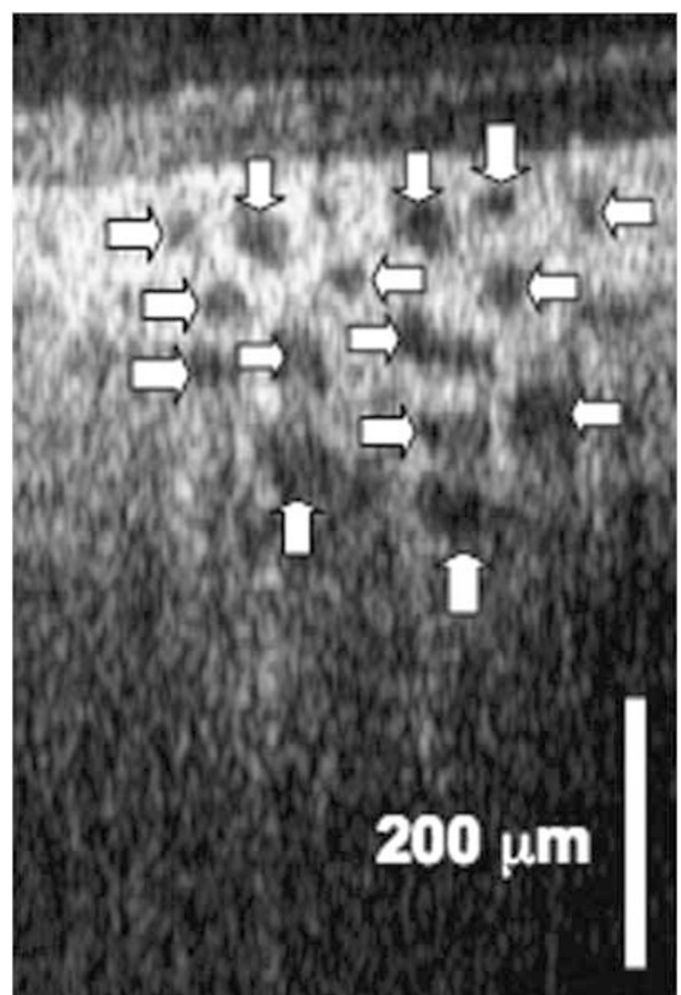

Figure 2 This OCT image reveals the uriniferous tubule lumens (indicated at arrows), cut at different angles, resulting in oblique and cross-sectional images through up to four or five layers of superficial uriniferous tubules. (the average tubular lumen size is $24.8 \pm 6.4 \mu \mathrm{m}, P=0.65$; comparing the lumen diameter measured from histology and OCT image). However, current resolution of our OCT system cannot distinguish between epithelium lining the tubule wall and intervening connective tissues.

\section{Renal Ischemia}

When the living kidney was rendered ischemic by applying gentle tension to a silk ligature looped around the renal artery, cells lining the uriniferous tubules swelled and the tubular lumens decreased in size (Figure 4). Using intensity thresholding, 3D visualization and volumetric rendering software, it was possible to visualize the tubular networks (Figure 5a and b; Supplementary Video 1) and quantify the differences in tubule luminal volumes before, during and following $20 \mathrm{~min}$ of ischemia (Figure 6). Tubule luminal volume decreases significantly during ischemia compared to baseline $(P=0.001$ for baseline $v s$ ischemia), and increases again $30 \mathrm{~min}$ after the reestablishment of blood flow ( $P=0.01$ for ischemia $v s$ reflow). The tubule luminal volume after $30 \mathrm{~min}$ recovery shows a slight decrease compared to that before ischemia ( $P=0.04$ for baseline $v s$ reflow).

\section{Mannitol Infusion}

Following an intravenous infusion of a single $1.0 \mathrm{ml}$ bolus containing 25\% mannitol, OCT images revealed a slight increase in the tubule luminal diameters $(28.7 \pm 5.0 \mu \mathrm{m})$ and
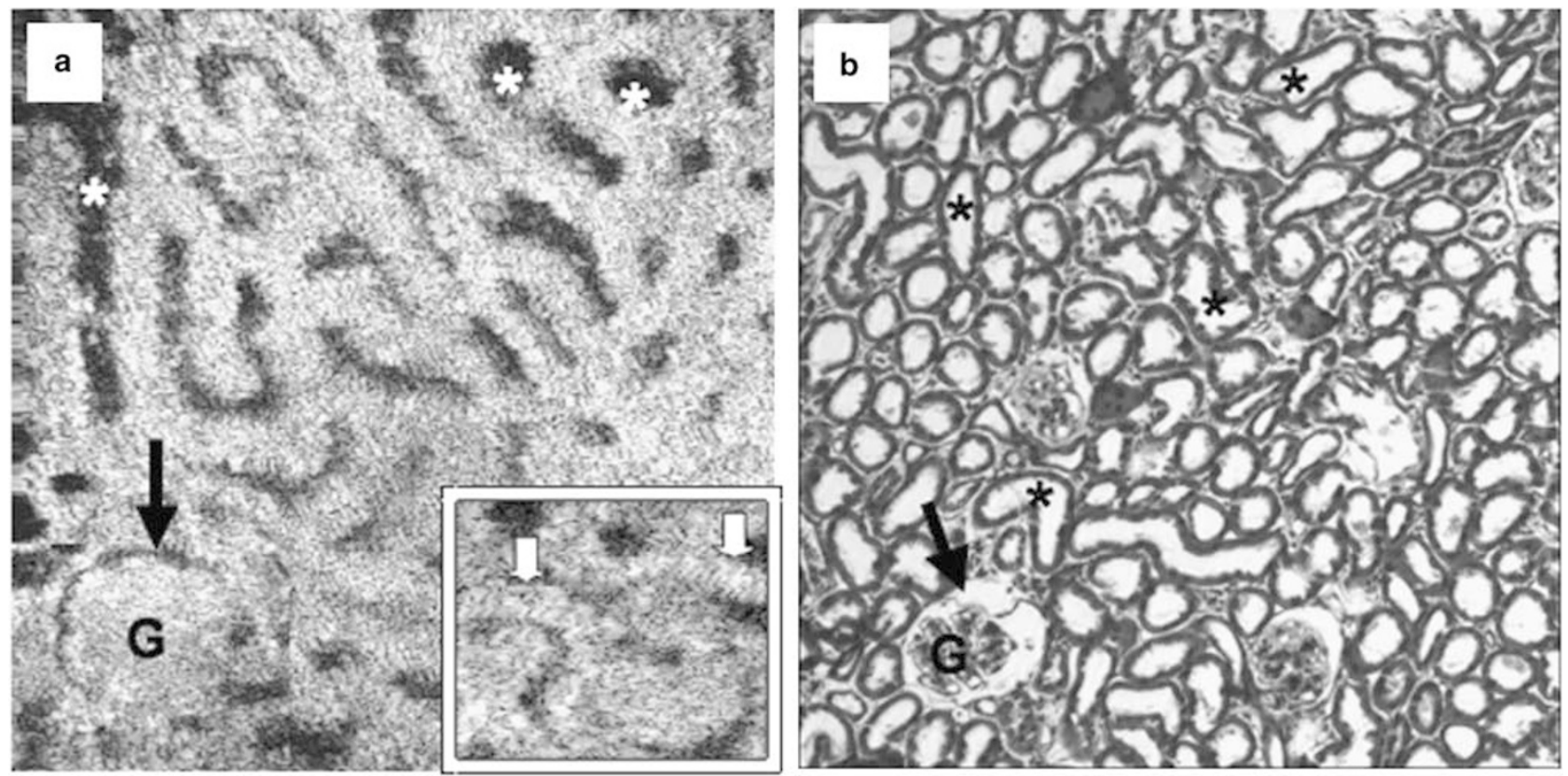

Figure 3 (a) En face OCT image of superficial uriniferous tubules prior to an ischemic insult. The tubular walls (appearing white) and lumens (appearing dark, some examples are indicated by ( $\left.x^{\prime}\right)$ are relatively uniform in their appearance. A glomerulus (G) can be seen in the lower left portion of the field. The small space between the glomerulus and the adjacent tissue represents the capsular space of Bowman (indicated by black arrow). The insert (lower right hand corner) shows a glomerulus together with what appear to be glomerular arterioles (white arrows). Barely visible are cross-striations in the arteriolar walls. Image size: $750 \mu \mathrm{m} \times 750 \mu \mathrm{m}$. (b) Corresponding histology of rat kidney showing tubular lumens (some indicated by ‘ $\times$ ), glomeruli (G) and capsular space of Bowman (indicated by arrow). Image size: $750 \times 750 \mu \mathrm{m}$. 


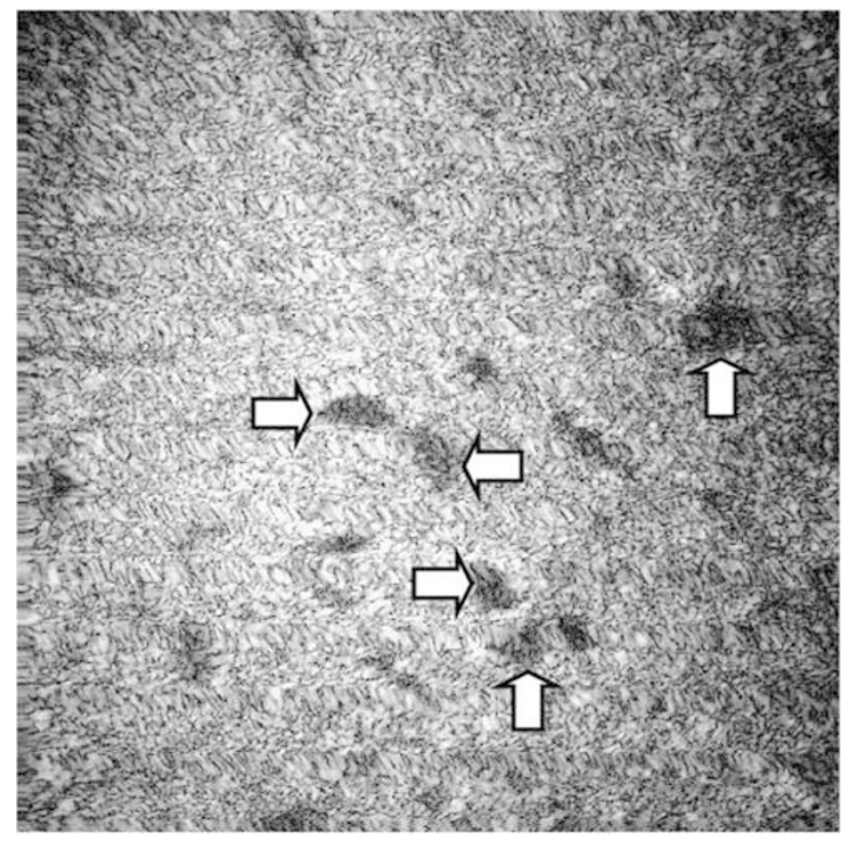

Figure 4 En face OCT image of the superficial uriniferous tubules taken following $15 \mathrm{~min}$ of normothermic renal ischemia. The remaining open lumens (arrows) are probably sections through distal tubules. Image size: $750 \times 750 \mu \mathrm{m}$.

a thinning of the tubular walls (Figure 7) compared with non-treated kidneys (see Figure 3a), however, the difference is not statistically significant $(P=0.07)$. Figure 8 is a $3 \mathrm{D}$ rendering of this same region, providing a different perspective of the tubular walls and lumens. When the mannitol treated kidney was rendered ischemic by applying tension to a ligature looped around the renal artery, the uriniferous tubules remained patent (Figure 9).

\section{Renal Preservation}

In this experiment, the objective was to determine whether OCT could document changes in the uriniferous tubules that occur while kidneys are being stored prior to their transplantation. Previous studies by us indicated that such changes will correlate with the post-transplant function of cold-stored kidneys. ${ }^{17}$ The kidneys were flushed in situ with a renal preservation solution consisting of a phosphate buffered solution containing $150 \mathrm{mOsm}$ of sucrose (ie, PBSuc $150)^{24,26,27}$ and stored at $0-4^{\circ} \mathrm{C}$ for $48 \mathrm{~h}$. During the first several hours of cold storage, the tubule lumens remained patent and appeared free of cytoplasmic debris (Figure 10a). However, unlike during normothermic ischemia, the coldpreserved kidney tubules also displayed an enhanced signal (increased brightness) of the lining epithelium (Figure 10a). Although it is not clear what this enhanced reflection represents, these regions appear to allow distinction of tubule walls from intervening peritubular capillary lumens (Figure 10a). As the storage time progresses, this enhanced reflective aspect of the tubular walls is lost and there is a
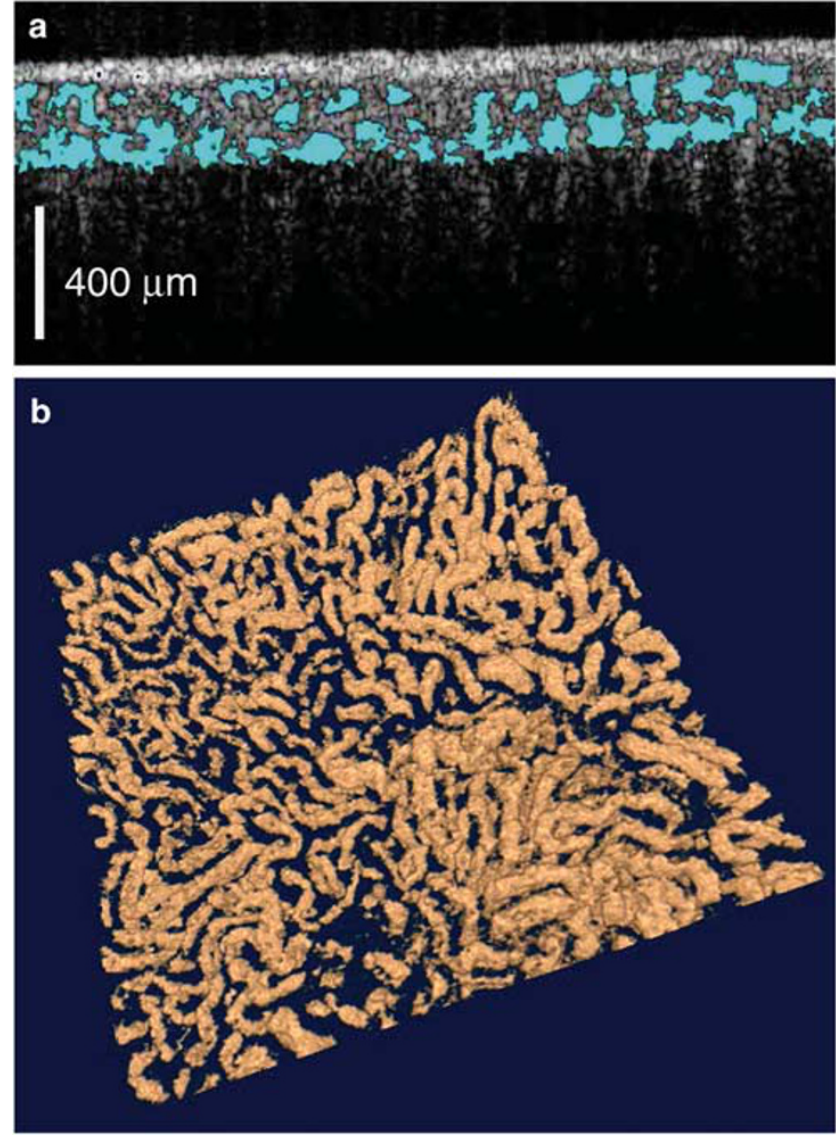

Figure 5 (a) A cross-sectional OCT image in which the tubule lumens have been segmented by intensity thresholding and highlighted in blue color (Bar $=400 \mu \mathrm{m}$ ). (b) A three-dimensional (3D) rendering of these lumens reconstructed from a series of cross-sections such as depicted in 'a' above (see Supplementary Video). Volume size: $2 \mathrm{~mm} \times 2 \mathrm{~mm} \times 300 \mu \mathrm{m}$.

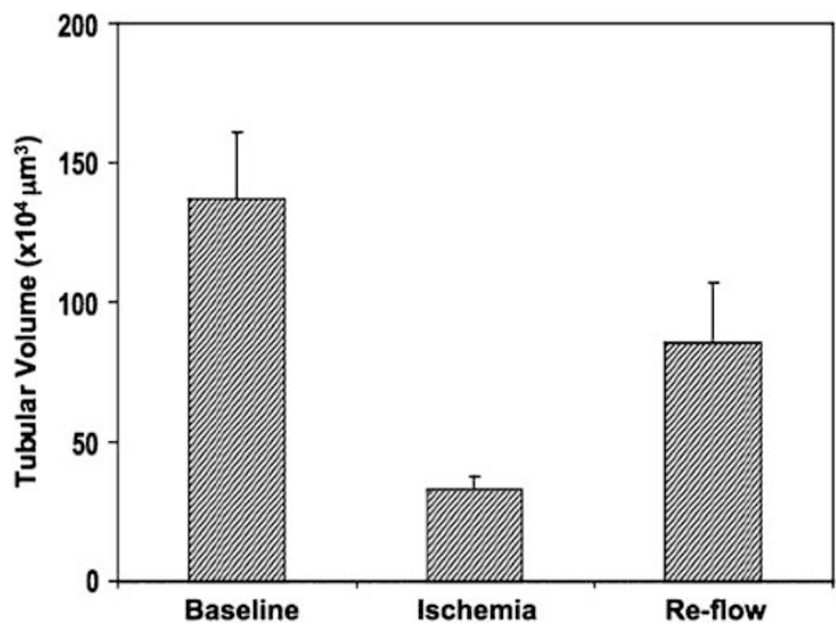

Figure 6 Comparison of the mean uriniferous tubule luminal volume before (baseline), during (ischemia) and following (reflow) $20 \mathrm{~min}$ of renal ischemia. The vertical axis represents the tubular lumen volume in 3D reconstructions such as depicted in Figure 5 ' $b$ '. Error bars represent s.d. 


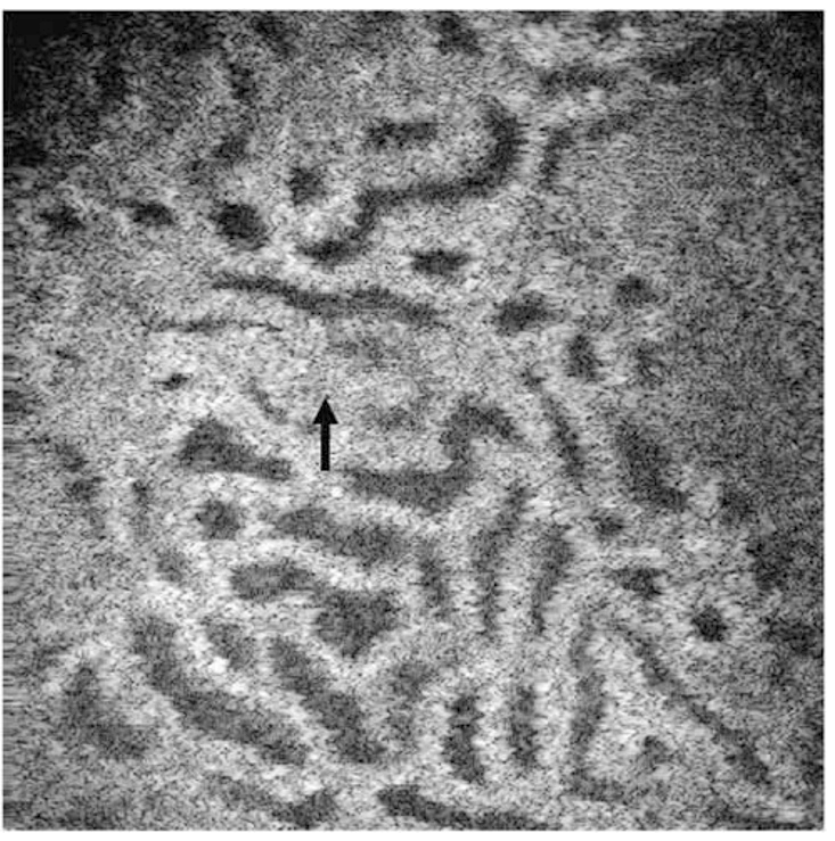

Figure 7 This en face OCT image of the superficial uriniferous tubules was taken $10 \mathrm{~min}$ following intravenous infusion of a single bolus of $1.0 \mathrm{ml}$ containing $25 \%$ of mannitol. Note that the tubule walls are thinner and the tubule lumens are expanded when compared with control samples (see Figure 3). In the center of the field is a glomerulus (arrow). Image size: $750 \times 750 \mu \mathrm{m}$.

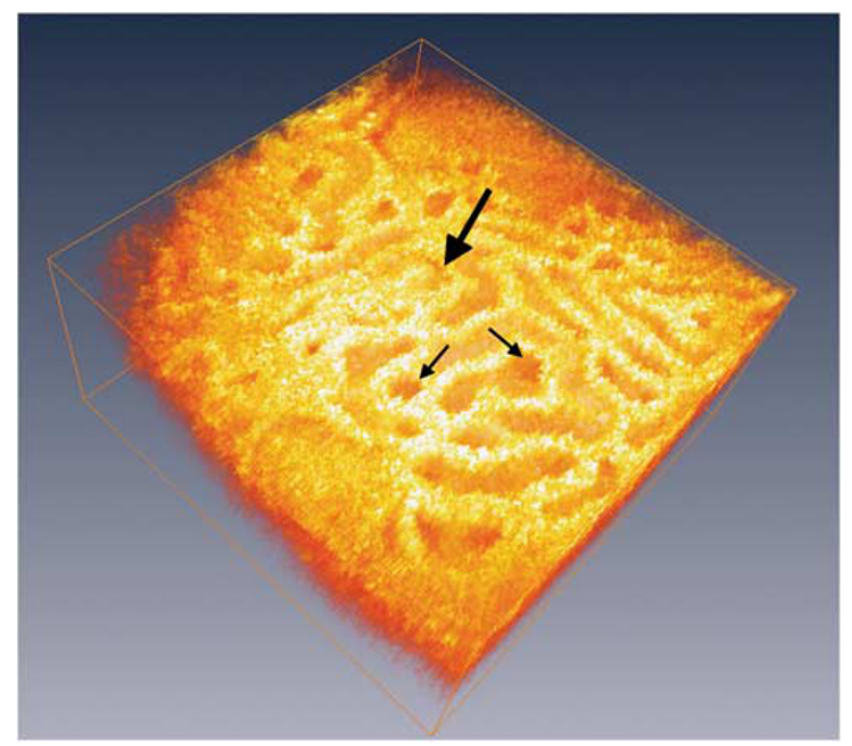

Figure 8 This figure is a 3D rendering of the same region as depicted in Figure 7. Three-dimensional imaging provides a good perspective of the tubule lumens (some at arrows) relative to the tubular walls. A glomerulus is at the large arrow.

significant change in tubular dimensions similar to that seen in response to normothermic ischemia (Figure 10b).

\section{DISCUSSION}

OCT is an emerging, non-invasive imaging modality that can generate cross-sectional and 3D images in situ and in

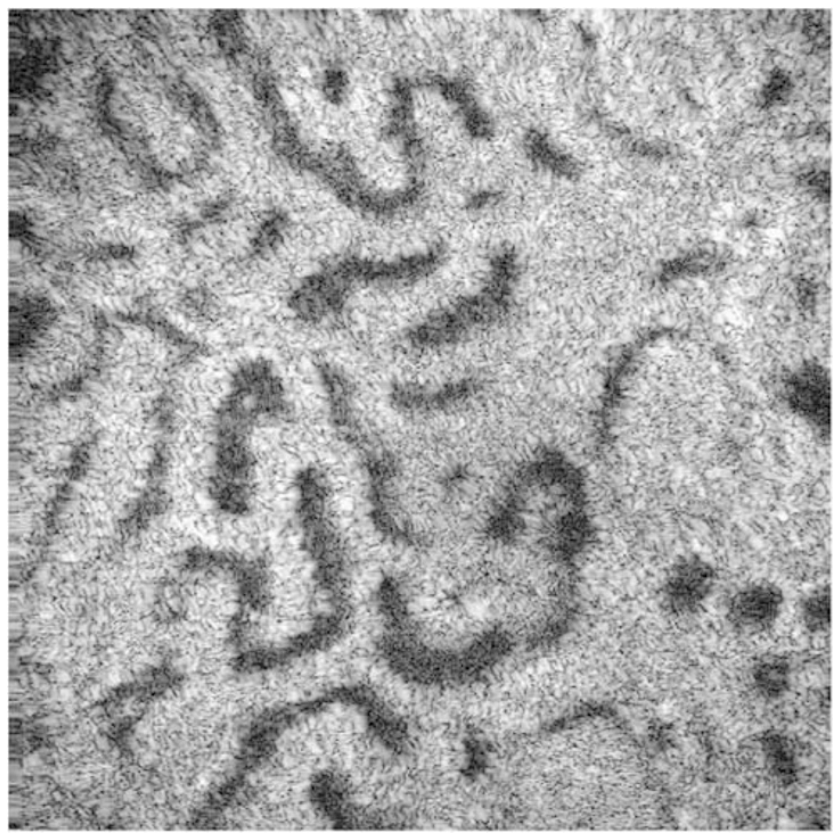

Figure 9 This en face OCT image of the superficial uriniferous tubules was taken of the mannitol treated kidney (see Figure 7) above, 15 min following induction of renal ischemia. Note that the tubule lumens remained patent due to prior treatment with mannitol. Image size: $750 \times 750 \mu \mathrm{m}$.

real-time. ${ }^{28}$ Although the degree of image penetration depth depends on a number of factors (light scattering properties of the tissue and confocal parameter of the focusing lens), compared with other in vivo real-time imaging methodo logies, such as standard confocal microscopy, tandem scanning confocal microscopy (TSCM), ${ }^{16}$ as well as near-infrared reflectance confocal microscopy, ${ }^{29}$ OCT has significantly improved depth penetration (ie, up to $1-2 \mathrm{~mm}$ ). ${ }^{30}$ Because OCT can operate with longer working distances than standard confocal microscopy (ie, $10 \mathrm{~mm}$ in the present investigation), tissue contact is not necessary. Finally, OCT can provide informative 3D images in arbitrary planes, and can be performed using a thin flexible endoscope or catheter ${ }^{3,4}$ or needle, ${ }^{31}$ thereby providing a sterile imaging probe and the possibility of imaging deep within a solid tissue.

In a previous study, we investigated the ability of OCT to image normal and pathologic rat kidney samples that had been fixed by vascular perfusion procedures ${ }^{14}$ to preserve in vivo tubular morphology. ${ }^{32}$ It is important to note that immersion fixation procedures associated with conventional surgical biopsies result in severe artifacts to the proximal tubule cells (ie, swelling and disruption of the tubule lining epithelium) that are difficult to distinguish from pathological changes in these tubules. ${ }^{32}$ Since in situ fixation procedures to preserve renal tubular morphology cannot be performed in the clinical setting, non-invasive microscopic procedures that will reveal in vivo renal microscopic anatomy are important for evaluating renal pathology. In our previous study, 

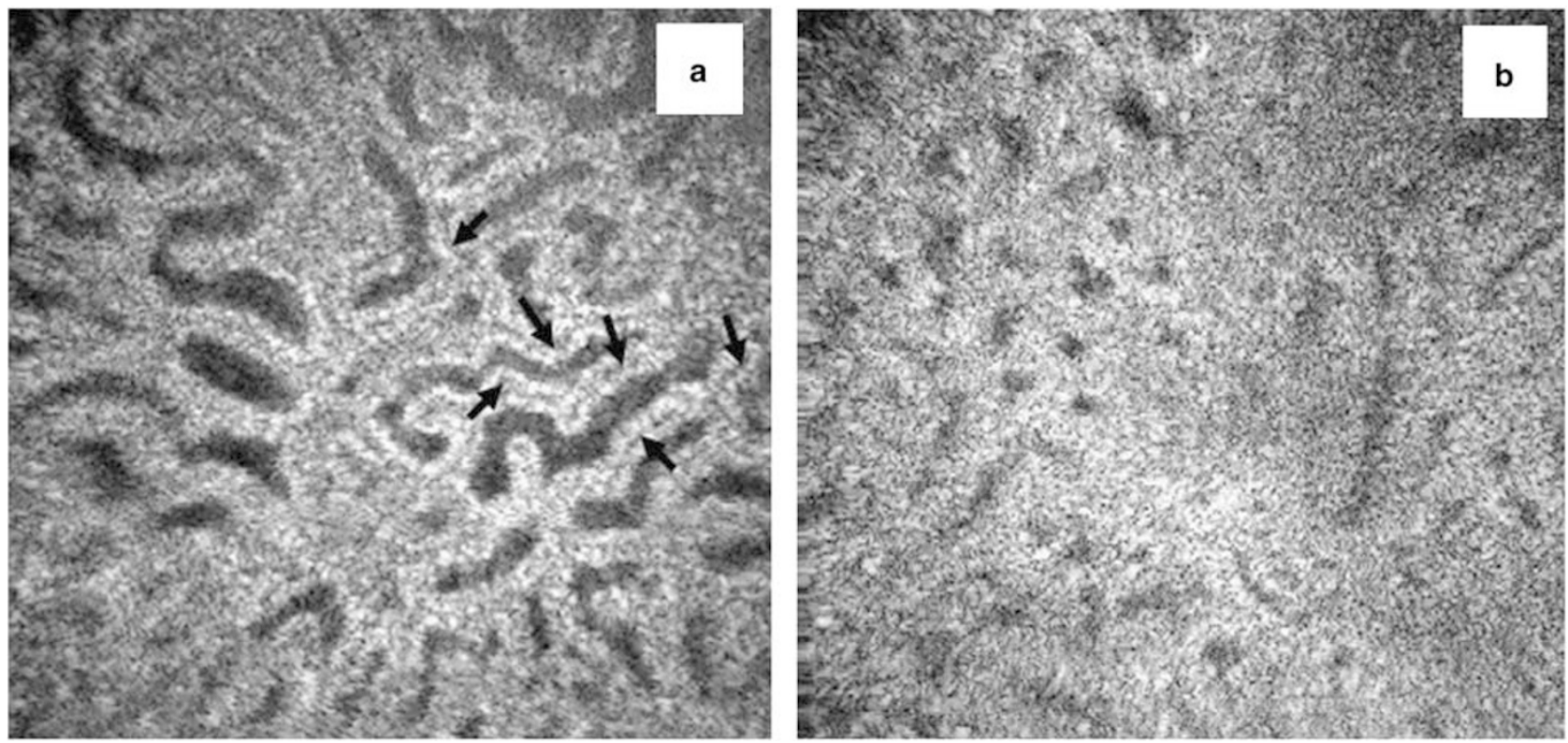

Figure 10 (a) This en face OCT image of the superficial uriniferous tubules was taken of a kidney that was flushed with PBSuc150 and stored for $1 \mathrm{~h}$ at $0-4{ }^{\circ} \mathrm{C}$. The tubule lumens remain patent and appear free of cytoplasmic debris. Note, also an enhanced reflection of the lining epithelium, which is in contrast to less reflective intertubular capillary spaces (arrows). Image size. $750 \times 750 \mu \mathrm{m}$. (b) This en face OCT image of superficial uriniferous tubules was taken of a kidney that was flushed with PBSuc150 and stored for $12 \mathrm{~h}$ at $0-4^{\circ} \mathrm{C}$. Tubule luminal sizes and the reflective nature of the lining epithelium have both decreased significantly compared with images taken earlier during cold storage of this same kidney (see Figure $10 \mathrm{a})$. Image size: $750 \times 750 \mu \mathrm{m}$.

we demonstrated that non-invasive OCT can provide unique and informative images of the kidney parenchyma and can detail pathological changes to the kidney associated with renal ischemia and mercury toxicity. ${ }^{14}$ Indeed, the $3 \mathrm{D}$ perspective provided by OCT is similar to those otherwise previously seen only using scanning electron microscopy. ${ }^{15}$

In general, OCT shows good agreement in terms of anatomical features compared to post-experimental morphological data. From previous literature, OCT imaging has shown precise correlation with the histological structures of the mucosa and the submucosa of the gastrointestinal (GI) tract, ${ }^{33}$ and satisfactory agreement in measurements of skin epidermal thickness between OCT images and histology performed using cryostat sections instead of paraffin embedding. ${ }^{34}$ In our previous ex vivo study of OCT imaging of the kidney, OCT correlates well with histology. ${ }^{14}$ In this study, we present a good correlation between the tubular diameter measured by OCT in vivo and that measured from conventional light microscopy. We would also like to mention again that OCT provides large numbers of crosssectional images that represent the full 3D structure of the tubules. In contrast, conventional light microscopy of biopsies provides a limited number of histological sections. Obtaining true 3D information using conventional histological procedures would require time-intensive and costly serial sectioning. Furthermore, since OCT can measure true tubule volume from a 3D data set, we expect this to be a more accurate measure than tubule volume calculated from the isolated cross-sectional images that are typically available from conventional light microscopy.

In the present study, we evaluated the ability of high-speed OCT to image the living kidney in situ, and its responses to renal ischemia, mannitol infusion and cold-storage preservation. A Munich-Wistar rat kidney model was chosen because it has superficial glomeruli accessible for observation, ${ }^{23}$ and has served as an in vivo model of choice for previous in situ microscopic imaging studies documenting the response of the living kidney to mannitol infusion and renal ischemia. ${ }^{16}$ Using OCT, we were able to image 300 $400 \mu \mathrm{m}$ into the kidney parenchyma, which is deep enough to see three or more layers of superficial uriniferous tubules. This is several times deeper than our previous study using a tandem scanning confocal microscope, which only permitted imaging a single superficial layer of uriniferous tubules. ${ }^{16}$

In the present study, we also imaged numerous glomeruli. Glomeruli are easily identified by their round shape and by the fact that they are separated from the surrounding parenchyma by the capsular space of Bowman. Because the size and shape of glomeruli changes significantly in some glomerular diseases, ${ }^{35-38}$ OCT may serve as a useful tool to detect such diseases. With its ability to image through a catheter or needle, OCT also has the potential of imaging glomeruli deeper in the kidney in addition to the superficial glomeruli. We also imaged what appeared to be afferent and efferent arterioles entering and leaving the renal corpuscle. These were identifiable by their size, shape and association 
with the renal corpuscle. Whether cross-striations observed in the arteriolar walls reflect movement or the spiral nature of arteriolar smooth muscle, is not yet clear.

Renal ischemia results in rapid cell swelling, especially in the kidney proximal convoluted tubules that make up most of the superficial parenchyma of the kidney cortex. This swelling leads to a significant decrease in tubule luminal diameters and irregularities in luminal outlines. ${ }^{16}$ As the ischemia-associated cell swelling progresses, the microvillous brush border lining the proximal tubules deteriorates and the lining cells eventually rupture. As a result of this cascade of events, tubule lumens become obliterated with cellular debris that prevents flow of filtrate through the nephron resulting in oliguria and acute renal failure. Since renal ischemia also results in damage to the third segment proximal tubules (ie, located in the outer stripe of the outer medulla) $)^{39,40}$ and the ascending thick segment of the proximal tubule (located in the inner stripe of the outer medulla) ${ }^{41}$ it is controversial as to which segment(s) of the nephron is/are most responsible for ischemia-induced acute renal failure. Nevertheless, a recent study by us indicated that characteristic changes in the morphology of superficial renal cortical proximal convoluted tubules correlate very accurately with post-transplant renal function. ${ }^{17}$ Indeed, this pathological information could be used to predict whether a donor kidney would exhibit immediate post-transplant function, delayed renal function or would not function at all following transplantation. ${ }^{17}$

Using high-speed OCT imaging, we were able to observe a similar gradual deterioration of the proximal convoluted tubules over time in response to normothermic ischemia. We were also able to quantify these changes and calculate mean luminal volumes prior to, during and following an ischemic insult. This is important because tubule luminal volume represents the most dramatic change in response to renal ischemia and one that has been used to predict the viability of cold-stored kidneys. ${ }^{17}$ The small tubular lumens remaining patent after prolonged ischemia most probably represent distal tubules. This conclusion is supported by another study that depicted distal tubules as remaining patent in response to the same renal model of ischemia as used in this study. ${ }^{16}$

Intravenous infusion of mannitol results in significant increases in glomerular filtration rate, ${ }^{42}$ which has been shown to result in an increase in tubule luminal diameters. ${ }^{16}$ In the present study, high-speed OCT imaging revealed these increases in the renal tubule luminal diameters in response to mannitol infusion. Mannitol also protects from renal ischemia by acting as an impermeant osmotic agent to prevent ischemia-induced cell swelling. ${ }^{24}$ This protection is due to the presence of the impermeant osmotic agent, mannitol, in the tubule lumens that counteracts the osmotic gradient resulting from the accumulation of small ions within tubule cells during ischemia (Gibbs-Donnan equilibrium). In the present study, high-speed OCT imaging documented the protection provided by mannitol infusion prior to inducing normothermic renal ischemia. Specifically, rats received an intravenous infusion of mannitol $10 \mathrm{~min}$ prior to rendering the kidneys ischemic by clamping the renal artery. This mannitol treatment prevented the rapid and dramatic cell swelling that otherwise resulted in a reduction and loss of tubule lumens in rats that had not received an infusion of mannitol. This means of protecting renal tubules from normothermic ischemia is the basis for preservation solutions developed to preserve kidneys and other organs while they are being stored prior to their transplantation. ${ }^{24}$ Indeed, mannitol was one of the first effective osmotic agents to be used in renal reservation and served as the effective osmotic agent in Sack's renal preservation solution. ${ }^{43}$ Nevertheless, as noted in our previous study of PBS150 cold-stored kidneys, over time kidneys preserved with cold-storage preservation solutions undergo swelling and a decrease in luminal diameters. ${ }^{24}$

To determine whether we could distinguish pathological changes in cold-stored kidneys, we imaged excised rat kidneys that had been flushed with a phosphate buffered solution containing $150 \mathrm{mOsm}$ of sucrose (ie, PBS150) and preserved in the cold (ie, $0-4^{\circ} \mathrm{C}$ ). Except for one unfortunately published study that used the wrong formula for PBS150, ${ }^{44}$ many studies have supported PBS150 (also made up as PBSuc 140) as being a very effective (and inexpensive) solution that preserves kidneys over extended periods of time. ${ }^{24,26,27}$ OCT examination of the PBS150 flushed cold-stored kidneys revealed gradual loss of proximal tubule luminal volume over time and in a manner similar to that seen in response to normothermic ischemia. We also noted an increase in the signal (ie, brightness) of the lining epithelium that allowed us to distinguish adjacent tubules from one another. We speculate that the latter might result from an increase in intercellular spaces shown by us to form during cold-storage preservation. ${ }^{45}$ If OCT can provide similar histopathological information regarding human donor kidneys harvested for transplantation, it has the potential of providing valuable real-time, non-invasive pathological information for predicting the post-transplant function of these donor kidneys. As such, the use of OCT to image donor kidneys may not only eliminate bad kidneys, but also permit the use of kidneys that might otherwise be discarded due to concerns regarding their viability (ie, long preservation times, kidneys from non-heart-beating donors, etc).

In summary, this investigation represents the first OCT study of the living kidney in situ. OCT effectively imaged the uriniferous tubules and their responses to renal ischemia and mannitol infusion. The sizes and shapes of renal corpuscles were also distinguished. The ability of OCT to provide noninvasive, cross-sectional and 3D real-time images of kidney histopathology may prove useful in a number of future applications including monitoring the status of donor kidneys prior to their transplantation.

Supplementary Information accompanies the paper on the Laboratory Investigation website (http://www.laboratoryinvestigation.org) 


\section{ACKNOWLEDGEMENT}

This research is supported, in part, by the National Institutes of Health RO1CA75289-09 and RO1-EY11289-21, Air Force Office of Scientific Research Medical Free Electron Laser Program FA9550-040-1-0046 and FA9550-0401-0011, National Science Foundation ECS-0501478 and BES-0522845. DCA acknowledges support from the Natural Sciences and Engineering Research Council of Canada and RH acknowledges support from the German Research Foundation (DFG Emmy Noether program HU1006/2-1).

1. Huang $D$, Swanson EA, Lin CP, et al. Optical coherence tomography. Science 1991;254:1178-1181.

2. Das A, Sivak MV, Chak A, et al. High-resolution endoscopic imaging of the Gl tract: a comparative study of optical coherence tomography vs high-frequency catheter probe EUS. Gastrointes Endosc 2001;54: 219-224.

3. Tearney GJ, Brezinski ME, Bouma BE, et al. In vivo endoscopic optical biopsy with optical coherence tomography. Science 1997;276: 2037-2039.

4. Herz PR, Chen Y, Aaron AD, et al. Ultrahigh resolution optical biopsy with endoscopic optical coherence tomography. Opt Express 2004; 12:3532-3542.

5. Hee MR, Izatt JA, Swanson EA, et al. Optical coherence tomography of the human retina. Arch Ophthalmol 1995;113:325-332.

6. Drexler W, Sattmann H, Hermann B, et al. Enhanced visualization of macular pathology with the use of ultrahigh-resolution optical coherence tomography. Arch Ophthalmol 2003;121:695-706.

7. Wojtkowski M, Srinivasan V, Fujimoto JG, et al. Three-dimensional retinal imaging with high-speed ultrahigh-resolution optical coherence tomography. Ophthalmology 2005;112:1734-1746.

8. Fujimoto JG, Boppart SA, Tearney GJ, et al. High resolution in vivo intra-arterial imaging with optical coherence tomography. Heart 1999;82:128-133.

9. Jang IK, Bouma $\mathrm{BE}$, Kang $\mathrm{DH}$, et al. Visualization of coronary atherosclerotic plaques in patients using optical coherence tomography: comparison with intravascular ultrasound. J Am Coll Cardiol 2002;39:604-609.

10. Bouma BE, Tearney GJ, Compton CC, et al. High-resolution imaging of the human esophagus and stomach in vivo using optical coherence tomography. Gastrointes Endoscopy 2000;51:467-474.

11. Sivak MV, Kobayashi K, Izatt JA, et al. High-resolution endoscopic imaging of the Gl tract using optical coherence tomography. Gastrointes Endoscopy 2000;51:474-479.

12. Li XD, Boppart SA, Van Dam J, et al. Optical coherence tomography: advanced technology for the endoscopic imaging of Barrett's esophagus. Endoscopy 2000;32:921-930.

13. Chen $Y$, Aguirre $A D$, Hsiung $P$, et al. Ultrahigh-resolution optical coherence tomography of Barrett's esophagus-preliminary descriptive clinical study correlating images with histology. Endoscopy 2007;39:599-605.

14. Chen $Y$, Andrews PM, Aguirre $A D$, et al. High-resolution threedimensional optical coherence tomography imaging of kidney microanatomy ex vivo. J Biomed Opt 2007;12:034008.

15. Andrews PM, Porter KR. A scanning electron microscopic study of the nephron. Am J Anat 1974;140:81-116.

16. Andrews PM. Tandem scanning confocal imaging of the living kidney. Int Rev Exp Patho 1996;36:131-143.

17. Andrews PM, Khirabadi BS, Bengs BC. Using tandem scanning confocal microscopy (TSCM) to predict the status of donor kidneys. Nephron 2002:91:148-155.

18. Choma MA, Sarunic MV, Yang $\mathrm{CH}$, et al. Sensitivity advantage of swept source and Fourier domain optical coherence tomography. Opt Express 2003;11:2183-2189.

19. Yun SH, Tearney GJ, de Boer JF, et al. High-speed optical frequencydomain imaging. Opt Express 2003;11:2953-2963.

20. Huber R, Wojtkowski M, Fujimoto JG. Fourier domain mode locking (FDML): A new laser operating regime and applications for optical coherence tomography. Opt Express 2006;14: 3225-3237.
21. Huber R, Adler C, Fujimoto JG. Buffered Fourier domain mode locking: Unidirectional swept laser sources for optical coherence tomography imaging at 370000 lines/s. Opt Lett 2006:31:2975-2977.

22. Adler DC, Huber R, Fujimoto JG. Phase-sensitive optical coherence tomography at up to 370000 lines per second using buffered Fourier domain mode locked lasers. Opt Lett 2007;32:626-628.

23. Hackbarth $\mathrm{H}$, Buttner $\mathrm{D}$, Jarck $\mathrm{D}$, et al. Distribution of glomeruli in the renal cortex of Munich Wistar Frömter (MWF) rats. Renal Physiol 1983;6:63-71.

24. Andrews PM, Coffey AK. Factors that improve the preservation of nephron morphology during cold storage. Lab Invest 1982;46: 100-120.

25. Andrews PM, Coffey AK. A technique to reduce fixation artifacts to kidney proximal tubules. Kidney Int 1984;25:964-968.

26. Pirie SC, Potts DJ. A comparison of the relative effectiveness of three transplant preservation fluids upon the integrity and function of rabbit proximal convoluted tubules perfused in vitro. Clin Sci 1986;70: 443-452.

27. Lam FT, Mavor AID, Potts DJ, et al. Improved 72-h renal preservation with phosphate-buffered sucrose. Transplantation 1989;47:767-771.

28. Fujimoto JG. Optical coherence tomography for ultrahigh resolution in vivo imaging. Nat Biotech 2003;21:1361-1367.

29. Campo-Ruiz V, Lauwers GY, Anderson RR, et al. Novel virtual biopsy of the kidney with near infrared, reflectance confocal microscopy: a pilot study in vivo and ex vivo. J Urol 2006;175:327-336.

30. Podoleanu AG. Optical coherence tomography. Brit J Radiol 2005;78:976-988.

31. Li X, Chudoba C, Ko T, et al. Imaging needle for optical coherence tomography. Opt Lett 2000;25:1520-1522.

32. Maunsbach $A B$. The influence of different fixatives and fixation methods on the ultrastructure of rat kidney proximal tubule cells. I. Comparison of different perfusion fixation methods and of glutaraldehyde, formaldehyde and osmium tetroxide fixatives. J Ultrastruc Res 1966;15:242-282.

33. Westphal V, Rollins AM, Willis J, et al. Correlation of endoscopic optical coherence tomography with histology in the lower-Gl tract. Gastrointes Endoscopy 2005;61:537-546.

34. Gambichler T, Moussa G, Regeniter $P$, et al. Validation of optical coherence tomography in vivo using cryostat histology. Phys Med Biol 2007;52:N75-N85.

35. Daiman S, Koni I. Glomerular enlargement in the progression of mesangial proliferative glomerulonephritis. Clin Nephrol 1998;49:145-152.

36. Nyberg $\mathrm{E}$, Bohmn S-O, Berg U. Glomerular volume and renal function in children with different types of nephrotic syndrome. Pediatr Nephrol 1994;8:285-289.

37. Gunderson HJ, Osterby R. Glomerular size and structure in diabetes mellitus. II. Late abnormalities. Dibetologia 1977;13:43-48.

38. Moran K, Mulhall J, Kelly D, et al. Morphological changes and alterations in regional intrarenal blood flow induced by graded renal ischemia. J Urology 1992;148:463-466.

39. Glaumann B, Trump BF. Studies on the pathogenesis of ischemic cell injury. III. Morphological changes of the proximal pars recta tubules (P3) of the rat kidney made ischemic in vivo. Virchows Arch B Cell Pathol 1975;19:303-323.

40. Venkatachalam MA, Bernard DP, Donohoe JF, et al. Ischemic damage and repair in the rat proximal tubule: differences among S1, S2 and S3 segments. Kidney Int 1978;14:31-49.

41. Brezis $M$, Rosen $S$, Silva $P$, et al. Renal ischemia: A new perspective. Kidney Int 1984;26:373-383.

42. Blantz RC. Effect of mannitol on glomerular ultrafiltration in the hydropenic rat. J Clin Invest 1974;54:1135-1143.

43. Sacks SA, Petritsch PH, Kaufman JJ. Canine kidney preservation using a new perfusate. Lancet 1973;1:1024-1028.

44. Ploeg RJ, Goossens D, Vreugdenhil P, et al. Successful 72-h cold storage kidney preservation with UW solution. Transplant Proc 1988;20:935-938.

45. Andrews PM. An evaluation of the ability of dextrans to reduce acute tubular necrosis during cold storage preservation. Transplantation 1994:57:1567-1575. 